\title{
PENGARUH ADOPSI E-COMMERCE TERHADAP KEBERHASILAN USAHA (STUDI KASUS PEDAGANG BATIK DI PASAR GROSIR SETONO)
}

\author{
Prastuti Sulistyorini, Nur Ika Royanti, Era Yunianto \\ STMIK WidyaPratama \\ Jl. Patriot 25 Pekalongan 12345 \\ Telp (0285)427816
}

\begin{abstract}
ABSTRAK
Effective strategies and targeted to business success of companies can be obtained if batik traders adopt e-commerce. According to the model Technology Accepatance Model (TAM) decision to adopt IT users are influenced by perceived usefulness and ease of use.

This study aims to explain the effect of the adoption of e-commerce to business success batik traders Setono Wholesale Market. Formulation of the problem in this research is the extent of adoption of ecommerce can provide benefits to batik traders Setono Wholesale Market, determine whether the benefits and ease of use factor significant and positive impact on the adoption of e-commerce, and e-commerce adoption is significant and positive impact on the success of business.

The sample used for hypothesis testing are 32 batik traders who already have a personal website. The sampling technique used is pusposive sampling technique. Testing research instruments using validity, reliability, and normality. Testing research hypotheses using regression analysis intervening. To process the data used SPSS version 17.

Results of hypothesis testing shows there is simultaneously a positive significant impact factor and ease of use of the benefits of e-commerce adoption, and there is a significant positive influence the adoption of e-commerce to business success.
\end{abstract}

Keyword : AdoptionE-commerce, TAM Model. 


\section{PENDAHULUAN}

Teknologi informasi saat ini berkembang merambah segala sendi kehidupan manusia. Peran teknologi informasi (TI) dalam bisnis juga semakin kuat. Kemajuan di bidang teknologi, komputer, dan telekomunikasi mendukung perkembangan teknologi internet. Dengan internet pelaku bisnis tidak lagi mengalami kesulitan dalam memperoleh informasi apapun, untuk menunjang aktivitas bisnisnya, bahkan sekarang cenderung dapat diperoleh berbagai macam informasi, sehingga informasi harus disaring untuk mendapatkan informasi yang tepat dan relevan. Hal tersebut mengubah abad informasi menjadi abad internet. Penggunaan internet dalam bisnis berubah dari fungsi sebagai alat untuk pertukaran informasi secara elektronik menjadi alat untuk aplikasi strategi bisnis, seperti: pemasaran, penjualan, dan pelayanan pelanggan (Yuliana, 2000). Penggunan internet dan world wide web (www) bagi perusahan saat ini sangat diperlukan. Setiap perusahan yang ingin memperluas jangkauan pemasaranya pasti mempunyai website, yang menjadi wahana promosi maupun transaksi bagi perusahan. Dengan adanya internet proses pemasaran dan penjualan dapat dilakukan setiap saat tanpa terikat ruang dan waktu (Jinling, Oktober 2009 dalam (Jauhari, April 2010)). Kini hampir semua lapisan masyarakat ( terutama di negara maju) sudah sangat terbiasa dengan web ini, karena hampir segala jenis informasi bisa diperoleh.

Teknologi informasi merupakan bentuk teknologi yang digunakan untuk menciptakan, menyimpan, mengubah, dan mengunakan imformasi dalam segala bentuknya. Melalui pemanfatan teknologi informasi ini, perusahaan dapat memasuki pasar global. Pemanfatan teknologi informasi dalam menjalankan bisnis atau sering dikenal dengan istilah $e$ - commerce bagi perusahan dapat memberikan fleksibiltas dalam produksi, mengirimkan dan menerima pesanan secara cepat dan hemat, serta mendukung transaksi cepat tanpa kertas. Pemanfatan internet memungkinkan pelaku usaha melakukan pemasaran dengan tujuan pasar global, sehinga peluang menembus ekspor sangat mungkin.

Electronic Commerce (ecommerce) merupakan konsep baru yang bisa digambarkan sebagai proses jual beli barang atau jasa pada World Wide Web Internet atau proses jual beli atau pertukaran produk, jasa dan informasi melalui jaringan informasi termasuk internet. Adopsi e-commerce, merupakan salah satu faktor yang penting untuk menunjang keberhasilan usaha. Keberhasilan usaha merupakan suatu proses peningkatan kuantitas dari dimensi perusahaan. Beberapa indikator keberhasilan usaha diantaranya peningkatan modal, peningkatan jumlah produksi, peningkatan jumlah pelanggan, perluasan usaha, perluasan daerah pemasaran, perbaikan sarana fisik, dan peningkatan pendapatan usaha (Benedicta Prihatin Dwi, 2003).

Dalam 5 (lima) tahun terakhir ini, industri yang sedang berkembang dan menjadi salah satu ikon di Indonesia adalah industri batik. Batik merupakan karya seni budaya bangsa Indonesia yang dikagumi dunia, patut dilestarikan 
kebudayaannya secara maksimal, dan batik merupakan industri kerajinan yang merupakan usaha turun-menurun dari generasi ke generasi. Peringatan hari Batik Nasional ditetapkan oleh pemerintah pada tanggal 2 Oktober 2009 seiring dengan ditetapkannya Batik sebagai warisan budaya dunia asli Indonesia oleh UNESCO PBB. Penetapan hari Batik Nasional tersebut mendapat apresiasi yang tinggi oleh Bangsa Indonesia, berbagai instansi pusat dan daerah menggunakan batik sebagai seragam kantor.

Kota Pekalongan yang dijuluki sebagai "Kota Batik" merupakan kota penghasil batik yang terkenal dan menjadi ikon batik di Jawa Tengah. Secara geografis, Kota Pekalongan digolongkan sebagai kota pesisir, dan produksi batik Kota Pekalongan sangat beragam dan sangat dinamis di dalam penerapan motif. Industri kecil maupun industri konveksi besar bersaing dalam pemasaran batik Pekalongan yang menyebar dan meluas di luar Kota Pekalongan. Industri batik memberikan sumbangan yang besar terhadap kemajuan perekonomian di Pekalongan dengan mayoritas dari home industry, sehingga Kota Pekalongan dikenal sebagai sentra industri batik nasional. Batik telah menjadi topangan hidup bagi sebagian besar masyarakat di Kota Pekalongan dan mendapatkan dukungan pemerintah dari segi bantuan dana sampai pengalokasian pedagang batik yang dijadikan satu lokasi, seperti misalnya pasar grosir batik setono.
Meskipun industri batik di Kota Pekalongan memberikan sumbangan yang besar terhadap kemajuan perekonomian di Pekalongan,industri batik belum berkembang secara maksimal. Faktor-faktor dominan yang membatasi perkembangan industri batik antara lain yaitu: persaingan (persaingan klaster, persaingan domestik dan persaingan luar negeri), penyelundupan, kebjakan ekonomi, kebijakan harga, permodalan dan manajerial, penguasaan teknologi, termasuk penguasaan Teknologi Informasi dan Komunikasi dalam upaya pengembangan bisnis. Permasalahan lain yang dihadapi pedagang batik saat ini adalah kesulitan dalam pemasaran. Ada dua tantangan utama bagi pengusaha dalam perdagangan internasional saat ini yaitu, akses pasar dan peningkatan daya saing. Penggunaan tenologi informasi dalam pemasaran produk batik adalah salah satu usaha untuk memperluas akses pasar. $E$ commerce merupakan salah satu cara yang dapat dilakukan oleh pedagang batik untuk memasarkan produknya selain dapat memperluas akses pasar. Pedagang batik harus melihat manfaat e-commerce untuk akses pasar secara mudah dan efisien seiring era globalisasi yang pasti akan dihadapi. Agar para pedagang batik di pasar grosir setono tidak tertinggal arus persaingan pasar global,dituntut untuk melakukan adopsi inovasi. Adopsi inovasi merupakan bagian dari strategi perusahaan. Strategi yang efektif dan tepat sasaran untuk meningkatkan keberhasilan usaha bisa didapat jika pedagang batik mengadopsi $e$ commerce. Sebagai bukti bahwa dengan adopsi e-commerce, 
pedagang batik akan memperoleh manfaat yang besar, beberapa peneliti telah melakukan penelitian diantaranya, menurut penelitian (Fatmariani, 2011) menunjukkan bahwa semakin tinggi adopsi teknologi informasi Open Source $e$ commerce dalam UKM, semakin tinggi pula kinerja UKM. Penelitian (Sevtian, 2011), menunjukkan besarnya pengaruh secara simultan antara e-commerce terhadap volume penjualan adalah sebesar $90,9 \%$ dan sisanya dipengaruhi oleh faktor lain. Hasil penelitian (Adi, 2008) menyebutkan bahwa penggunaan TIK di kalangan UKM India dan hadirnya website telah menghasilkan peningkatan pendapatan.

Berdasarkan latar belakang tersebut, perlu dilakukan penelitian mengenai adopsi e-commerce pedagang batik pasar grosir setono. Penelitian ini bertujuan untuk mengetahui sejauhmana adopsi $e$ commerce dapat memberikan manfaat kepada pedagang batik, mengetahui pengaruh faktor manfaat dan kemudahan penggunaan terhadap adopsi $e$ commercepedagang batik, dan mengetahui pengaruh adopsi $e$ commerce terhadap keberhasilan usaha pedagang batik.

\section{METODE PENELITIAN}

\subsection{Jenis Penelitian}

Jenis penelitian ini termasuk penelitian survei, dan dalam pengambilan kesimpulan dilakukan dengan melalui pengujian hipotesis.

\subsection{Objek Penelitian}

Obyek penelitian ini adalah pedagang batik di pasar grosir setono. Menurut pendapat (Malhotra, 2005), jumlah responden paling sedikit 4 atau 5 kali jumlah variabel yang digunakan didalam penelitian, sehingga jumlah sampel yang digunakan dalam penelitian ini sebesar 150 pedagang batik. Dari hasil kuesioner yang dibagikan kepada 150 pedagang batik, hanya 32 pedagang batik yang memiliki $e$ commercedengan website pribadi milik perusahaan.Sehingga untuk menguji apakah terdapat pengaruh adopsi e-commerce terhadap keberhasilan usaha pedagang batik, sampel yang digunakan sebanyak 32 pedagang batik. Penetapan sampel dilakukan dengan teknik purposive sampling method, dimana pengambilan sampel ditentukan secara sengaja/sesuai dengan masalah penelitian.

\subsection{Metode Pengumpulan Data}

Metode pengumpulan data dilakukan dengan :

1. Kuesioner

Pencarian data dilakukan dengan membagi kuesioner kepada pedagang batik di pasar grosir setono.

2. Wawancara

Wawancara dilakukan untuk mendapatkan gambaran yang lebih detail mengenai obyek penelitian.

\subsection{Variabel Penelitian dan Definisi Operasional Variabel}

Variabel yang terdapat dalam penelitian ini adalah variabel terikat (dependen) dan variabel bebas (Independen). Variabel bebas adalah variabel yang mempengaruhi variabel lain, sedangkan variabel terikat adalah variabel yang dipengaruhi oleh variabel lain. 
Variabel terikat pada penelitian ini adalah Adopsi e-commerce, dan Keberhasilan Usaha, dan variabel bebas pada penelitian ini yaitu Manfaat, Kemudahan Penggunaan. Variabel ini diukur dengan menggunakan skala likert interval 5 dengan instrumen yang dikembangan sendiri oleh peneliti yang terdiri dari tiga pertanyaan.

1. Variabel Manfaat.

Menurut (Davis, 1986) dalam (Fatmariani, 2011) manfaat dioperasional sebagai suatu tingkat atau keadaan dimana seseorang yakin bahwa dengan menggunakan teknologi informasi e-commerce akan meningkatkan kinerjanya.

2. Variabel Kemudahan Penggunaan.

Menurut (Davis, 1986) dalam (Fatmariani, 2011), kemudahan penggunaan dioperasionalkan sebagai suatu tingkat atau keadaan dimana bahwa seseorang yakin bahwa dengan menggunakan teknologi informasi e-commerce tidak memerlukan tidak membutuhkan usaha yang besar pada saat digunakan (free of effort).

3. Variabel Adopsi E-commerce.

Menurut (Roger, 1995)Adopsi merupakan keputusan untuk menggunakan ide baru secara tetap dalam skala yang luas. Adopsi e-commerce dioperasionalkan sebagai proses penerimaan inovasi produk $e$ commerce.

4. Variabel Keberhasilan Usaha.

Menurut (Benedicta Prihatin Dwi, 2003)keberhasilan usaha dioperasionalkan sebagai pencapaian yang diharapkan di dalam bisnis. Indikator yang keberhasilan usaha dalam hal ini diindikasikan dalam lima hal yaitu jumlah penjualan meningkat, hasil produksi meningkat, keuntungan atau profit bertambah, perkembangan dan pertumbuhan usaha berkembang cepat dan memuaskan. Indikator keberhasilan usaha dalam penelitian ini meliputi penjualan meningkat, pangsa pasar meningkat, dan pendapatan bertambah.

\subsection{Metode Analisis Data}

Setelah semua data penelitian didapatkan, selanjutnya diketahui alat analisis data dan pengujian hipotesis yang diuraikan sebagai berikut :

\section{Uji Validitas}

Untuk mengukur sejauhmana kecermatan dan ketepatan suatu instrumen pengukuran (kuesioner) dalam mengukur variabel $\left(\mathrm{X}_{1}\right)$, variabel $\left(\mathrm{X}_{2}\right)$ terhadap variabel $\left(\mathrm{Y}_{1}\right)$ dan variabel $\left(\mathrm{Y}_{2}\right)$ dilakukan uji validitas dan reliabilitas. Uji Validitas dilakukan untuk mengetahui seberapa baik suatu instrumen mengukur konsep yang seharusnya diukur. Alat ukur yang digunakan dalam pengujian validitas adalah daftar pertanyaan yang telah diisi oleh responden dan akan diuji hasilnya guna menunjukkan valid tidaknya suatu data. Kuesioner dikatakan valid apabila koefisien korelasi product moment melebihi 0,3, (Sugiyono, 2009). Variabel yang akan diuji dalam penelitian ini adalah manfaat, kemudahan penggunaan, adopsi e-commerce dan keberhasilan usaha. 
2. Uji Reliabilitas.

Uji Reliabilitas dilakukan untuk mengetahui tingkat konsistensi hasil pengukuran bila dilakukan pengukuran dua kali atau lebih terhadap gejala yang sama dengan alat ukur yang sama. Hasilnya ditunjukkan oleh sebuah indeks yang menunjukkan seberapa jauh alat ukur yang dapat dipercaya atau dapat diandalkan. Uji ini diterapkan untuk mengetahui responden telah menjawab pertanyaan-pertanyaan secara konsisten atau tidak sehingga kesungguhan jawaban dapat dipercaya. Untuk menguji reliabilitas instrumen penelitian ini digunakan Cronbach Alpha (Ghozali, 2007). Dalam hal ini apabila nilai koefisien alpha $>0,6$ maka dapat dikatakan bahwa instrumen yang digunakan tersebut reliabel. Proses pengujian dilakukan sebelum penelitian sebenarnya dilakukan dan butir pertanyaan yang tidak valid dan tidak reliabel tidak akan digunakan dalam penelitian ini.

3. Uji Normalitas.

Pengujian ini dilakukan sebelum analisis regresi agar kondisi estimator linear tidak bias yang terbaik (best linear unbias estimator). Pengujian normalitas dilakukan untuk mengetahui normal tidaknya suatu distribusi data. Model regresi yang baik adalah memilki distribusi data normal atau mendekati normal. Pada penelitian ini, uji normalitas dilakukan dengan dengan metode uji one - sample Kosmogorov smirnov, dimana jika Asyim-sig (2 tailed) $>0,05$ maka dapat dikatakan bahwa data berdistribusi normal (Ghozali, 2007).

4. Analisis Regresi Liner Dengan Variabel Intervening.

Metode analisis pada penelitian ini menggunakan perhitungan regresi intervening dimana untuk dipergunakan melihat pengaruh tidak langsung antara satu variabel terhadap variabel yang lain. Variabel intervening merupakan variabel antara atau mediating, yang berfungsi memediasi hubungan antara variabel independent (predictor) dengan variabel dependen (predictand).Untuk

menyelesaikan persamaan regresi linier dengan variabel intervening digunakan software SPSS versi 17. Analisis ini menggunakan 2 sub struktur :
a. Sub Struktur Pertama : Adopsi E-commerce dipengaruhi oleh Manfaat dan Kemudahan Penggunaan.

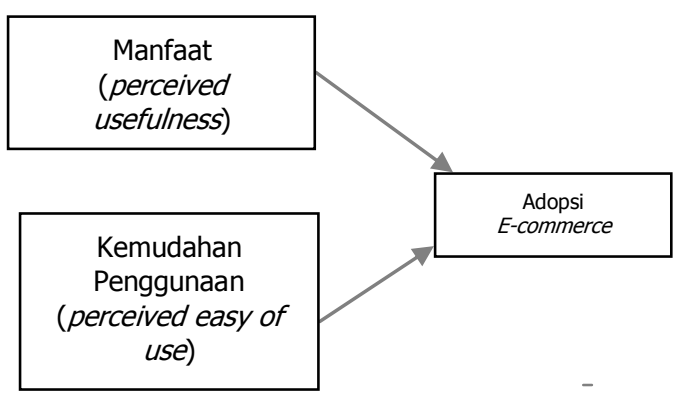

Gambar 3.1 : Adopsi Ecommerce dipengaruhi Manfaat dan Kemudahan Penggunaan.

Persamaannya :

$$
\hat{\mathbf{Y}}_{1}=\mathbf{a}+\mathbf{b}_{1} \cdot \mathbf{X}_{1}+\mathbf{b}_{2} \cdot \mathbf{X}_{2}+\mathbf{e}
$$

Keterangan :

$\hat{Y}_{1} \quad$ : Variabel Adopsi E-commerce

a : konstanta 
$\mathrm{b}_{1}-\mathrm{b}_{2} \quad$ : koefisien regresi masing-masing variabel

$\mathrm{X}_{1} \quad$ : Manfaat

$\mathrm{X}_{2}$ : Kemudahan Penggunaan

e : error

\section{b. Sub Struktur Kedua : Keberhasilan Usaha dipengaruhi oleh Adopsi E- commerce.}

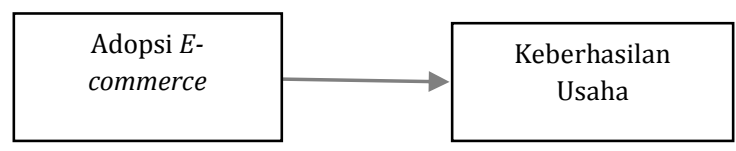

Gambar 3.2 : Keberhasilan Usaha Dipengaruhi Adopsi E-commerce

Persamaannya :

$\hat{\mathbf{Y}}_{2}=\mathbf{a}+\mathrm{b} 1 . \mathbf{Y} 1+\mathrm{e}$

Keterangan :

$\hat{Y}_{2}$ : Variabel Keeberhasilan Usaha

a : konstanta

$\mathrm{b}_{1}$ : koefisien regresi

Y1 : Adopsi E-commerce

e : error

\section{HASIL DAN PEMBAHASAN}

\subsection{Gambaran Umum Objek Penelitian}

Sejarah pasar grosir itu berawal 1940-an sewaktu beberapa perajin batik di Kampung Setono ingin membentuk wadah, dan baru diformalkan tahun 1962 menjadi Koperasi Pengrajin Batik Setono (KPBS). Koperasi tersebut memiliki peran besar terhadap kemajuan industri batik dan akselerasi perekonomian di Pekalongan, dan bahkan Batang.

Koperasi itu berkembang pesat hingga bisa membangun pabrik mori bahan baku batik di lokasi yang kini jadi pasar grosir. Dulu, orang menyebutnya koperasi batik atau pabrik mori di Jalan Raya Baros.
Bahkan tahun 1962, Wapres Moh Hatta sebagai Bapak Koperasi meresmikan berbagai fasilitas yang dibangun koperasi tersebut.

Tahun 1980 usaha pabrik mori itu kembang-kempis hingga akhirnya gulung tikar. Persaingan dengan pabrik mori di kota lain dan kemunculan batik cap menjadi salah satu penyebab kebangkrutan tersebut. Pabrik mori menjadi tidak terurus dan bangunannya terbengkalai.

Akhir 1990, Drs Soni Hikmalul MSi (ketua), Priyanto (sekretaris) dan $\mathrm{H}$ Hasanudin (bendahara) Nagari, yang dulu menjadi mitra usaha KPBS berinisiatif menyulap eks pabrik mori KPBS menjadi pasar batik. Embrio itu tumbuh dengan pesat dan tanggal 8 Juli 2000 tempat itu diresmikan dengan nama Pasar Grosir Batik Setono oleh Wali Kota Samsudiat.

Pasar Grosir Setono yang berkembang menjadi sedikitnya 300 kios dengan 600 pedagang batik perlu terus berbenah. Tantangannya adalah bagaimana membuat pengunjung merasa puas, dan mempromosikannya dari mulut ke mulut. Dalam era TIK, pengelola bisa memanfaatkan internet untuk memasarkan produk dari tempat itu.

\subsection{Profil Pedagang Batik Pasar Grosir Setono}

Berdasarkan data yang diperoleh dari pembagian kuesioner kepada 150 pedagang batik didapat bahwa $74 \%$ pedagang batik sudah menjalankan usahanya lebih dari 5 tahun. Untuk memberikan gambaran yang jelas mengenai profil lama usaha pedagang batik pasar grosir 
setono, dapat diihat pada Gambar 1.1 berikut :

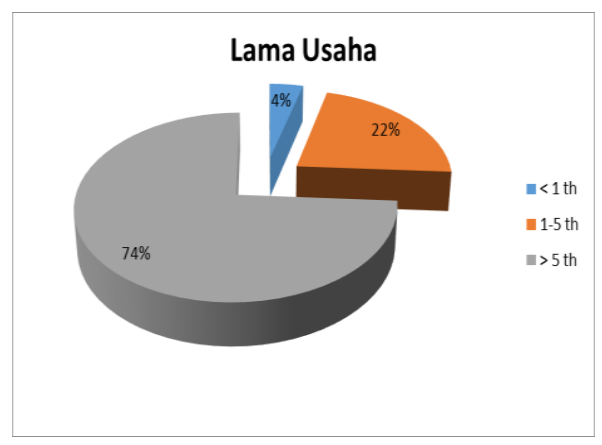

Gambar 1.1 Profil Pedagang Batik Berdasarkan Lama Usaha

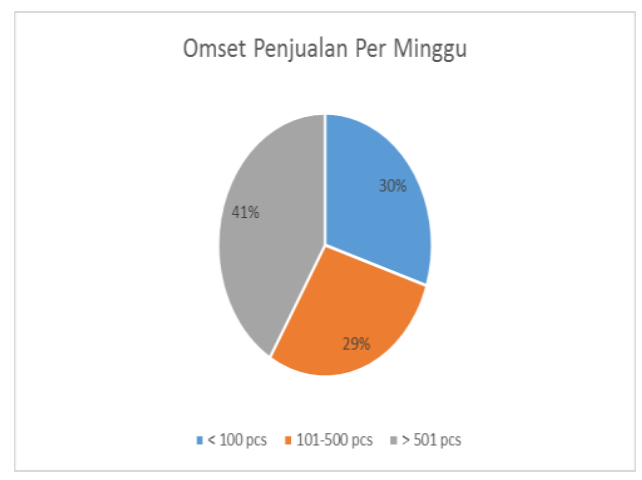

Dari gambar 1.1 dapat diketahui bahwa jumlah pedagang batik yang telah menjalankan bisnisnya dengan lama lama usaha $<1$ th sebesar sebesar 5\% (6 pedagang), lama usaha $1-5$ th $23 \%$ ( 33 pedagang), dan lama usaha $>5$ th 72\% (111pedagang).

Untuk area penjualan, dilaporkan bahwa $55 \%$ pedagang batik pasar grosir setono masih menjual produk batik disekitar dalam kota. Untuk Untuk memberikan gambaran yang jelas mengenai area penjualan dapat dilihat pada Gambar 1.2 berikut :

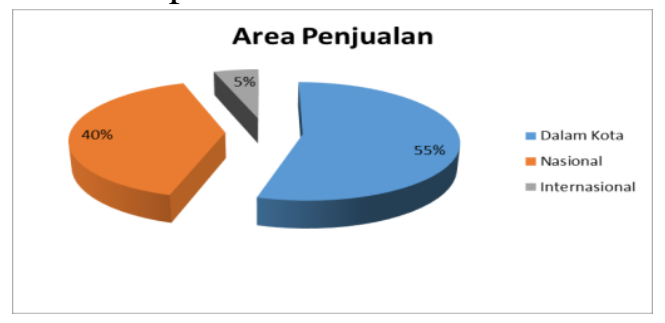

Gambar 1.2 Profil Pedagang Batik Berdasarkan Area Penjualan

Dari gambar 1.2 dapat diketahui bahwa area penjualan yang dijangkau oleh pedagang batik meliputi dalam kota, nasional, dan internasional. Adapun prosentase pedagang batik dengan area penjualan dalam kota sebesar 55\% (82 pedagang), prosentase pedagang batik dengan area penjualan nasional sebesar $40 \%(60$ pedagang), dan prosentase pedagang batik dengan area penjualan hingga skala internasional sebesar 5\% ( 8 pedagang).

Untuk data omset per minggu dapat dilihat pada Gambar 1.3 berikut :

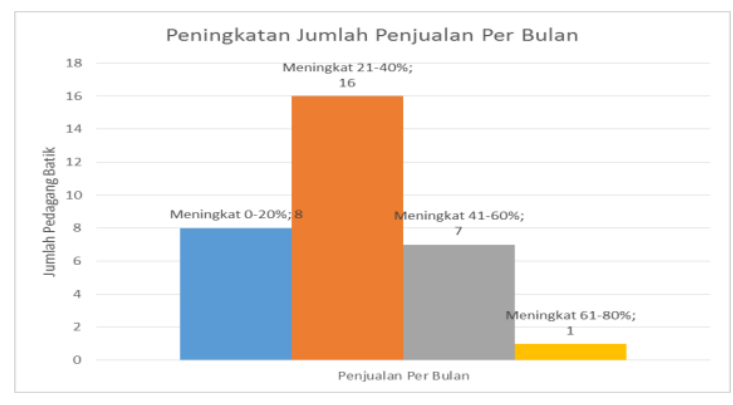

Gambar 1.3 Profil Pedagang Batik Berdasarkan Omset Penjualan Per Minggu

Dari gambar 1.3 dapat dilihat bahwa prosentase pedagang batik dengan omset per minggu kurang dari 100 pcs sebesar $30 \%$ (45 pedagang), prosentase pedagang batik dengan omset per minggu lebih dari 501 pcs sebesar $41 \%$ ( 62 pedagang), dan prosentase pedagang batik dengan omset per minggu antara antara 101 - 400 pcs sebesar 29\% ( 43 pedagang). 
Untuk data mengenai cara pedagang batik dalam menjual produknya dapat dilihat pada gambar 1.4 berikut :

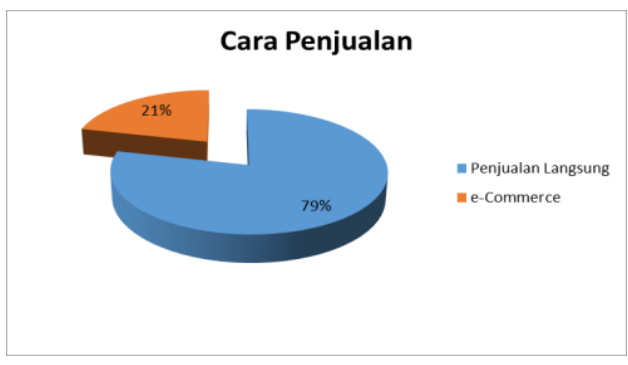

Gambar 1.4. Profil Pedagang

BatikBerdasarkan Cara Penjualan

Dari gambar 1.4 dapat dilihat bahwa prosentase pedagang batik yang melakukan penjualan secara langsung sebesar 79\% ( 118 pedagang), dan yang telah menggunakan e-commerce untuk menjual batik sebesar 21\% ( 32 pedagang).

Untuk data perangkat teknologi informasi yang digunakan dalam penjualan dapat dilihat pada gambar berikut :

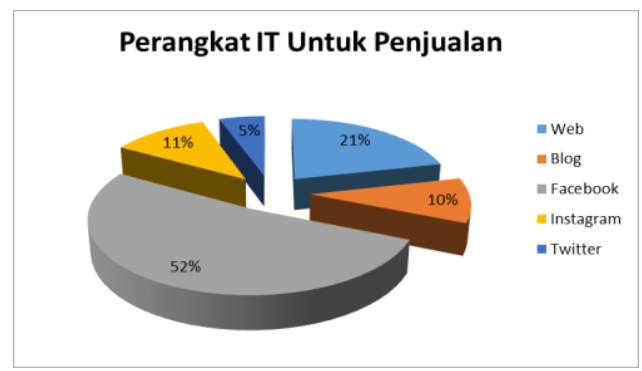

\section{Gambar 1.5 Profil Kepemilikan} Perangkat TI Untuk Penjualan

Berdasarkan gambar 1.5 dapat dilihat bahwa prosentase pedagang batik yang memiliki web untuk penjualan sebesar sebesar $21 \%$ (32 pedagang), memiliki blog sebesar $10 \% \quad(15$ pedagang), memiliki facebook sebesar $52 \%$ (78 pedagang), memiliki instagram sebesar $11 \%(17$ pedagang), dan memiliki twiter sebesar 5\% (8 pedagang).

\subsection{Keberhasilan Usaha Pedagang Batik Dengan Adopsi $E$ - commerce.}

Berdasarkan data yang diperoleh dari pembagian kuesioner kepada 32 pedagang batik yang sudah memiliki e-commerce dengan website pribadi milik perusahaan didapat bahwa setelah mengadopsi e-commerce, terjadi peningkatan penjualan. Untuk memberikan gambaran yang jelas mengenai peningkatan penjualan setelah adopsi e-commerce, dapat diihat pada Gambar 1.6 berikut :

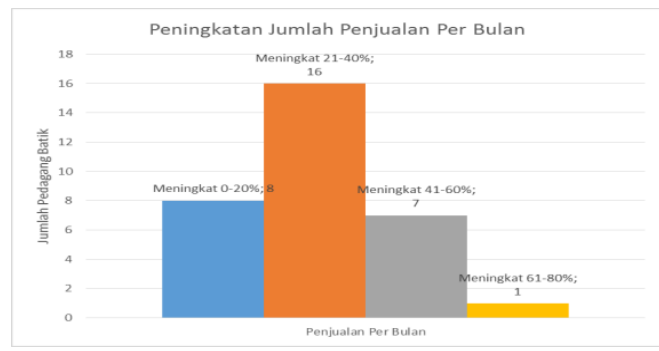

Gambar 1.6 Peningkatan Jumlah Penjualan Per Bulan

Berdasarkan gambar 1.6 dapat diketahui bahwa 8 pedagang batik melaporkan adopsi e-commerce dapat meningkatkan jumlah penjualan per bulan hingga 20\%, 16 pedagang batik melaporkan adopsi e-commerce dapat meningkatkan jumlah penjualan per bulan antara $21-40 \%, 7$ pedagang batik melaporkan adopsi e-commerce dapat meningkatkan jumlah penjualan per bulan antara 41 $60 \%$, dan 1 pedagang batik melaporkan dengan adopsi $e$ commerce dapat meningkatkan jumlah penjualan per bulan antara $61-80 \%$. 


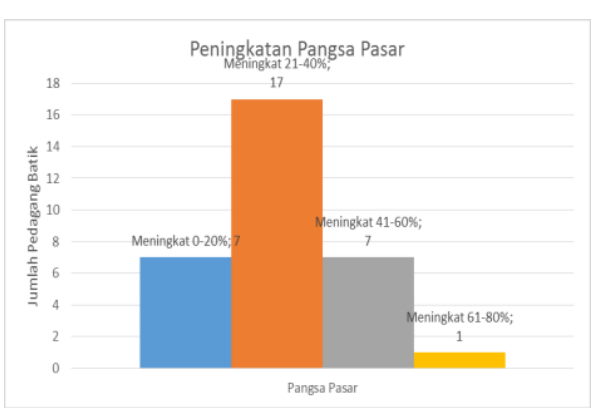

Gambar 1.7 Peningkatan Pangsa Pasar

Berdasarkan gambar 1.7 dapat diketahui bahwa 7 pedagang batik melaporkan adopsi e-commerce dapat meningkatkan pangsa pasar hingga 20\%, 17 pedagang batik melaporkan adopsi e-commerce dapat meningkatkan pangsa pasar antara $21-40 \%, 7$ pedagang batik melaporkan adopsi e-commerce dapat meningkatkan pangsa pasar antara $41-60 \%$, dan 1 pedagang batik melaporkan dengan adopsi $e$ commerce dapat meningkatkan pangsa pasar antara $61-80 \%$.

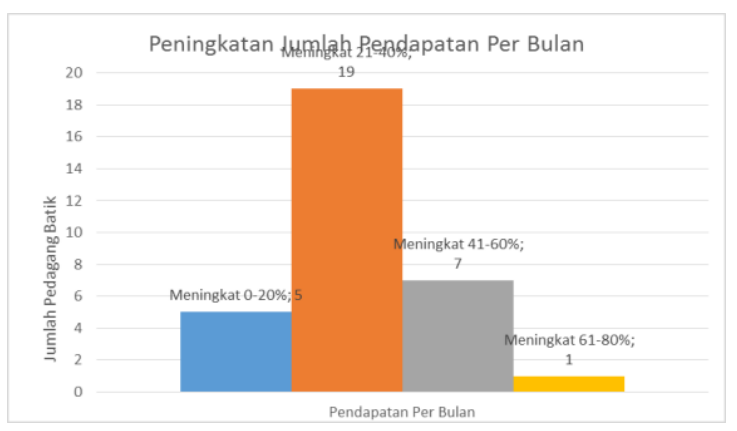

Gambar 1.8 Peningkatan Jumlah Pendapatan Per Bulan

Berdasarkan gambar 1.8 dapat diketahui bahwa 5 pedagang batik melaporkan adopsi e-commerce dapat meningkatkan jumlah pendapatan per bulan 20\%, 19 pedagang batik melaporkan adopsi e-commerce dapat meningkatkan jumlah pendapatan per bulan antara $21-40 \%, 7$ pedagang batik melaporkan adopsi e-commerce dapat meningkatkan jumlah pendapatan per bulan antara 41 $60 \%$, dan 1 pedagang batik melaporkan dengan adopsi $e$ commerce dapat meningkatkan jumlah pendapatan per bulan antara $61-80 \%$.

\subsection{Hasil Pengukuran Sikap Responden}

\section{a. Hasil Pengukuran Sikap Responden Pada Variabel Manfaat.}

\begin{tabular}{|c|c|c|}
\hline JAWABAN & JUMLAH & PROSENTASE \\
\hline STS & 0 & 0 \\
\hline TS & 3 & 3,125 \\
\hline N & 16 & 16,66667 \\
\hline S & 43 & 44,79167 \\
\hline SS & 34 & 35,41667 \\
\hline TOTAL & 96 & 100 \\
\hline
\end{tabular}

Analisa output :

Dari hasil jawaban responden mengenai faktor manfaat didapatkan 77 pedagang batik $(80,2 \%)$ menyatakan sangat setuju dan setuju bahwa adopsi $e$ commerce bermanfaat.

\section{b. Hasil Pengukuran Sikap Responden Pada Variabel Kemudahan Penggunaan.}

\begin{tabular}{|c|c|c|}
\hline JAWABAN & JUMLAH & PROSENTASE \\
\hline STS & 0 & 0 \\
\hline TS & 4 & 4,166667 \\
\hline N & 6 & 6,25 \\
\hline S & 67 & 69,79167 \\
\hline SS & 19 & 19,79167 \\
\hline TOTAL & 96 & 100 \\
\hline
\end{tabular}

Analisa output :

Dari hasil jawaban responden mengenai kemudahan Pengunaan didapatkan 86 pedagang batik $(89,6 \%)$ menyatakan sangat setuju dan setuju bahwa e-commerce mudah digunakan. 


\section{c. Hasil Pengukuran Sikap Responden Pada Adopsi E- commerce}

\begin{tabular}{|c|c|c|}
\hline JAWABAN & $\begin{array}{c}\text { JUMLA } \\
\mathrm{H}\end{array}$ & PROSENTASE \\
\hline STS & 0 & 0 \\
\hline TS & 5 & 5,208333 \\
\hline $\mathrm{N}$ & 12 & 12,5 \\
\hline $\mathrm{S}$ & 43 & 44,79167 \\
\hline SS & 36 & 37,5 \\
\hline TOTAL & 96 & 100 \\
\hline
\end{tabular}

Analisa output :

Dari hasil jawaban responden mengenai adopsi e-commerce didapatkan 79 pedagang batik $(82,3 \%)$ menyatakan sangat setuju dan setuju bahwa adopsi $e$ commerce dapat meningkatkan penjualan, pangsa pasar dan pendapatan.

\section{d. Hasil Pengukuran Sikap Responden Pada Keberhasilan Usaha}

\begin{tabular}{|c|c|c|}
\hline JAWABAN & JUMLAH & PROSENTASE \\
\hline STS & 0 & 0 \\
\hline TS & 2 & 2,083333 \\
\hline N & 7 & 7,291667 \\
\hline S & 59 & 61,45833 \\
\hline SS & 28 & 29,16667 \\
\hline TOTAL & 96 & 100 \\
\hline
\end{tabular}

Analisa output :

Dari hasil jawaban responden mengenai keberhasilan usaha didapatkan 87 pedagang batik $(90,6 \%)$ menyatakan sangat setuju dan setuju bahwa dengan adopsi $e$ commerce dapat membantu dalam meningkatkan keberhasilan usaha.

\subsection{Pembahasan Hasil Penelitian}

\section{Pengujian Instrumen Penelitian}

Berdasarkan metode analisis data yang telah dijelaskan pada metode penelitian, pengujian pertama yang dilakukan pada penelitian ini adalah uji instrumen penellitian. Pengujian instrumen penelitian ini dilakukan dengan validitas, reliabilitas dan uji normalitas Kolmogorov Smirnov.

\section{a. Uji Validitas}

Uji validitas menunjukkan sejauh mana ketepatan dan kecermatan suatu alat ukur dalam melakukan fungsi ukurnya (Sugiyono, 2009). Adapun caranya adalah dengan mengkorelasikan antara skor yang diperoleh pada masing-masing item pertanyaan dengan skor total variabelnya.

Pengujian validitas dilakukan dengan bantuan komputer menggunakan program SPSS for Windows versi 17. Dalam penelitian ini pengujian validitas dilakukan terhadap 32 pedagang batik yang telah menggunakan $e$ commerce dari 150 pedagang batik yang dijadikan sampel. Kriteria keputusan sebuah butir pertanyaan dikatakan valid jika koefisien korelasi product moment melebihi 0,3 (Sugiyono, 2009). Adapun hasil pengolahan data tersebut sebagai berikut :

\section{1) Uji Validitas instrumen} variabel variabel $\mathrm{X}_{1}$ (Manfaat).

Berdasarkan hasil pengolahan data diperoleh hasil sebagai berikut:

Tabel 1.1

Uji validitas instrumen variabel $\mathrm{X}_{1}$

(Manfaat)

\begin{tabular}{|l|c|c|}
\hline Instrumen & Sign r-hitung & Ketr. \\
\hline Pertanyaan 1 & 0,000 & Valid \\
\hline Pertanyaan 2 & 0,000 & Valid \\
\hline Pertanyaan 3 & 0,000 & Valid \\
\hline
\end{tabular}


Berdasarkan tabel di atas menunjukkan bahwa semua indikator pertanyaan valid

2) Uji validitas instrumen variabel $\mathrm{X}_{2}$ (Kemudahan Penggunaan) Berdasarkan hasil pengolahan data diperoleh hasil sebagai berikut:

Tabel 1.2

Uji validitas instrumen variabel $\mathrm{X}_{2}$ (Kemudahan Penggunaan).

\begin{tabular}{|c|c|c|}
\hline Instrumen & Sign r-hitung & Ketr. \\
\hline Pertanyaan 1 & 0,000 & Valid \\
\hline Pertanyaan 2 & 0,000 & Valid \\
\hline Pertanyaan 3 & 0,000 & Valid \\
\hline
\end{tabular}

Berdasarkan tabel di atas menunjukkan bahwa semua indikator pertanyaan valid

1. Uji validitas instrumen variabel $\mathrm{Y}_{1}$ (Adopsi E-commerce)

Berdasarkan hasil pengolahan data diperoleh hasil sebagai berikut:

Tabel 1.3

Uji validitas instrumen variabel $\mathrm{Y}_{1}$ (Adopsi E-commerce)

\begin{tabular}{|c|c|c|}
\hline Instrumen & Sign r-hitung & Ketr. \\
\hline Pertanyaan 1 & 0,000 & Valid \\
\hline Pertanyaan 2 & 0,000 & Valid \\
\hline Pertanyaan 3 & 0,000 & Valid \\
\hline
\end{tabular}

Berdasarkan tabel di atas menunjukkan bahwa semua indikator pertanyaan valid.

2. Uji validitas instrumen variabel $\mathrm{Y}_{2}$ (Keberhasilan Usaha).

Berdasarkan hasil pengolahan data diperoleh hasil sebagai berikut:

Tabel 1.4
Uji validitas instrumen variabel $\mathrm{Y}_{2}$ (Keberhasilan Usaha)

\begin{tabular}{|c|c|c|}
\hline Instrumen & Sign r-hitung & Ketr. \\
\hline Pertanyaan 1 & 0,000 & Valid \\
\hline Pertanyaan 2 & 0,000 & Valid \\
\hline Pertanyaan 3 & 0,000 & Valid \\
\hline
\end{tabular}

Berdasarkan tabel di atas menunjukkan bahwa semua indikator pertanyaan valid.

b. Uji Reliabilitas

Setelah dilakukan uji validitas selanjutnya dilakukan uji Reliabilitas untuk mengetahui tingkat konsistensi hasil pengukuran bila dilakukan pengukuran dua kali atau lebih terhadap gejala yang sama dengan alat ukur yang sama. Hasilnya ditunjukkan oleh sebuah indeks yang menunjukkan seberapa jauh alat ukur yang dapat dipercaya atau dapat diandalkan.

Untuk menguji reliabilitas instrument penelitian ini digunakan Cronbach Alpha (Sugiyono, 2009). Dalam hal ini apabila nilai koefisien alpha $\geq 0,6$ maka dapat dikatakan bahwa instrumen yang digunakan tersebut reliabel. Responden telah menjawab pertanyaan-pertanyaan secara konsisten atau tidak sehingga kesungguhan jawaban dapat dipercaya.

Pengujian reliabilitas dilakukan dengan bantuan komputer menggunakan program SPSS for Windows versi 17. Dalam penelitian ini pengujian reliabilitas dilakukan terhadap 32 responden yang diperoleh dari hasil kuesioner yang dapat diolah. Adapun hasil pengolahan data tersebut sebagai berikut : 
Tabel 1.5

Uji Reliabilitas

\begin{tabular}{|l|c|c|}
\hline \multicolumn{1}{|c|}{ Variabel } & $\begin{array}{c}\text { Cronbach } \\
\text { Alpha }\end{array}$ & Keterangan \\
\hline Manfaat & 0,684 & Reliabel \\
\hline $\begin{array}{l}\text { Kemudahan } \\
\text { Penggunaan }\end{array}$ & 0,612 & Reliabel \\
\hline Adopsi E-commerce & 0,720 & Reliabel \\
\hline Keberhasilan Usaha & 0,720 & Reliabel \\
\hline
\end{tabular}

Berdasarkan tabel diatas semua data memiliki Cronbach Alpha > 0,6 berarti data tersebut reliabel.

\section{c. Pengujian Normalitas}

Pengujian yang dilakukan untuk mengetahui normal tidaknya suatu distribusi data. Model regresi yang baik adalah memilki distribusi data normal atau mendekati normal.

Pada penelitian ini, uji normalitas dilakukan dengan menggunakan bantuan software SPSS versi 17 dengan menggunakan metode uji one sample Kosmogorov smirnov, dimanajika Asyim-sig (1 tailed) >0,05 maka dapat dikatakan bahwa data berdistribusi normal (Sugiyono, 2009). Pengujian normalitas ini didapat nilai sign 0,944> 0,05 (level of signifikan) artinya data yang diolah dinyatakan normal

\section{Pengujian Hipotesis}

Metode analisis pada penelitian ini menggunakan perhitungan regresi intervening dimana untuk dipergunakan melihat pengaruh tidak langsung antara satu variabel terhadap variabel yang lain. Variabel intervening merupakan variabel antara atau mediating, yang berfungsi memediasi hubungan antara variabel independent (predictor) dengan variabel

dependen (predictand).Untuk menyelesaikan persamaan regresi linier digunakan software SPSS versi 17. Analisis ini menggunakan 2 sub struktur :

1. Sub Struktur Pertama :

Adopsi E-commerce dipengaruhi oleh Manfaat dan Kemudahan Penggunaan, dapat dilihat pada gambar berikut :

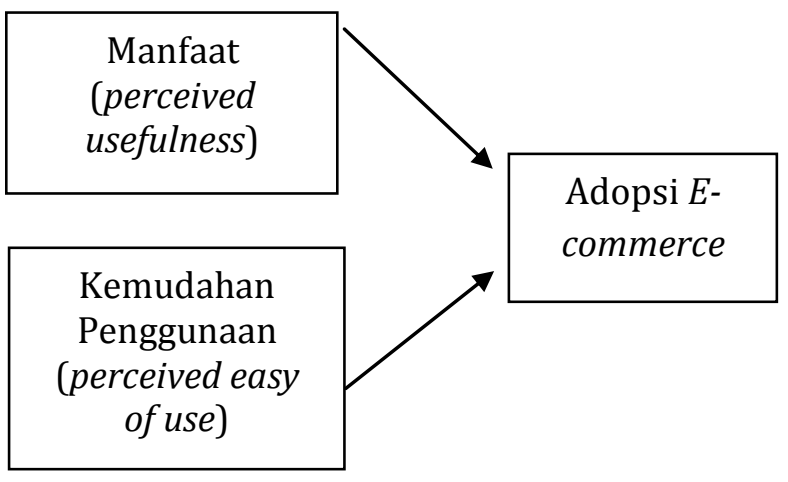
Gambar 1.9 Kerangka Sub Struktur
Pertama

Persamaannya :

$\hat{\mathbf{Y}}_{1}=\mathbf{a}+\mathbf{b}_{1} \cdot \mathbf{X}_{1}+\mathbf{b}_{2} \cdot \mathbf{X}_{2}$

$+\mathbf{e}$

Keterangan :

$\hat{\mathrm{Y}}_{1}$ : Variabel Adopsi

E-commerce

a : konstanta

$b_{1}-b_{2}$ : koefisien regresi masing-masing variabel

$\mathrm{X}_{1} \quad$ : Manfaat

$\mathrm{X}_{2}$ : Kemudahan

Penggunaan

e : error

1. Sub Struktur Kedua : Keberhasilan Usaha dipengaruhi oleh Adopsi Ecommerce, dapat dilihat pada gambar berikut :

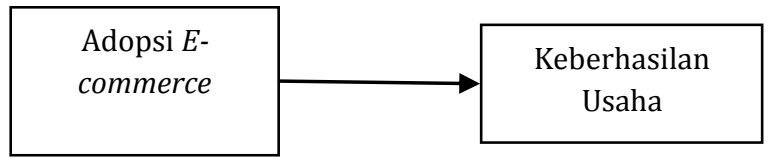


Gambar 1.10 Kerangka

Sub Struktur Kedua

Persamaannya :

$\hat{\mathbf{Y}}_{2}=\mathbf{a}+\mathbf{b 1} . \mathbf{Y}_{1}+\mathbf{e}$

Keterangan :

$\hat{Y}_{2} \quad$ : Variabel Keberhasilan Usaha

a : konstanta

$\mathrm{b}_{1} \quad$ : koefisien regresi

Y1 : Adopsi E-commerce

e : error

\section{Analisis Sub Struktur Pertama dan Sub Struktur Kedua \\ 1. Analisis Sub Struktuk Pertama}

Analisa output :

1. Nilai $\mathrm{R}$ atau Koefisien Korelasi sebesar 0,640 artinya hubungan antara variabel manfaat $\left(\mathrm{X}_{1}\right)$, variabel kemudahan penggunaan $\left(\mathrm{X}_{2}\right)$, dan variabel Adopsi E-commerce $\left(\mathrm{Y}_{1}\right)$ adalah Hubungan yang kuat.

2. Nilai $\mathrm{R}$ Square atau Koefisien Determinasi $\left(\mathrm{R}^{2}\right)$ sebesar 0,409 artinya $40,9 \%$ variabel manfaat $\left(\mathrm{X}_{1}\right)$, dan variabel kemudahan penggunaan $\left(\mathrm{X}_{2}\right)$ berpengaruh terhadap variabel Adopsi E-commerce ( $\left.\mathrm{Y}_{1}\right)$, sedangkan sisanya $59,1 \%$ dipengaruhi variabel lain yang tidak diteliti.

Uji F (F-test)

Uji F (F-test) dimaksudkan untuk mengetahui pengaruh variabel independen (Manfaat dan Kemudahan Penggunaan) secara simultan (bersama sama) terhadap variabel tak bebas (Adopsi E-commerce).

Analisa Output :

Berdasarkan Uji $F$ atau uji simultan didapat nilai $\mathrm{F}$ yaitu 10.034 dengan sig $0,000<0,05$ (level of significant) maka dinyatakan menolak Ho artinya secara simultan (bersama) terdapat pengaruh signifikan dan positif antara variabel Manfaat $\left(\mathrm{X}_{1}\right)$, variabel Kemudahan Penggunaan $\left(\mathrm{X}_{2}\right)$, dan variabel Adopsi E-commerce $\left(\mathrm{Y}_{1}\right)$

Analisa Output :

1. Dari olah data tersebut didapat persamaan regresi linier sebagai berikut : $\mathrm{Y}_{1}=-1.314+0.549 \mathrm{X}_{1}+$ $0.565 \mathrm{X}_{2}+$ e. Arti persamaan tersebut adalah Konstanta -1.314 menyatakan jika tidak ada Manfaat $\left(\mathrm{X}_{1}\right)$ dan Kegunaan $\left(\mathrm{X}_{2}\right)$ maka Adopsi $E$ commerce $\quad\left(\mathrm{Y}_{1}\right)$ sebesar $\quad-1.314$. Koefisien Regresi 0.549 menyatakan bahwa setiap penambahan 1 point Manfaat $\left(\mathrm{X}_{1}\right)$, maka Adopsi $E$ commerce $\left(\mathrm{Y}_{1}\right)$ akan meningkat sebesar 0.565. Koefisien Regresi 0.565 menyatakan bahwa setiap penambahan 1 point Kemudahan Penggunaan $\left(\mathrm{X}_{2}\right)$, maka Adopsi $E$ commerce $\left(\mathrm{Y}_{1}\right)$ akan meningkat sebesar 0.565 .

2. Untuk uji parsial $X_{1}$ didapat nilai signifikan $0,001<0,05$ (level of significant) maka dinyatakan menolak Ho artinya secara parsial terdapat pengaruh signifikan dan positif antara variabel Manfaat $\left(\mathrm{X}_{1}\right)$ dan variabel Adopsi E-commerce $\left(\mathrm{Y}_{1}\right)$.

3. Untuk uji parsial $\mathrm{X}_{2}$ didapat nilai signifikan $0,019<0,05$ (level of significant) maka dinyatakan menolak Ho artinya secara parsial terdapat pengaruh signifikan dan positif antara variabel Kemudahan Penggunaan $\left(\mathrm{X}_{2}\right)$ dan variabel Adopsi E-commerce $\left(\mathrm{Y}_{1}\right)$.

\section{Analisis Sub Struktur Kedua}


Analisa output :

1. Nilai $\mathrm{R}$ atau Koefisien Korelasi sebesar 0,608 artinya hubungan antara variabel Adopsi E-commerce $\left(\mathrm{Y}_{1}\right)$, dan variabel Keberhasilan Usaha $\left(\mathrm{Y}_{2}\right)$, adalah Hubungan yang kuat.

2.

ilai $\mathrm{R}$ Square atau Koefisien Determinasi $\left(\mathrm{R}^{2}\right)$ sebesar 0,370 artinya $37 \%$ variabel Adopsi $E$ commerce $\left(\mathrm{Y}_{1}\right)$, berpengaruh terhadap variabel Keberhasilan Usaha $\left(\mathrm{Y}_{2}\right)$, sedangkan sisanya $63 \%$ dipengaruhi variabel lain yang tidak diteliti.

Analisa Output :

Berdasarkan Uji $F$ atau uji simultan didapat nilai $\mathrm{F}$ yaitu 17.6204 dengan sig $0,000<0,05$ (level of significant) maka dinyatakan menolak Ho artinya secara simultan (bersama) terdapat pengaruh signifikan dan positif antara variabel Adopsi E-commerce $\left(\mathrm{Y}_{1}\right), \quad$ dan Keberhasilan Usaha $\left(\mathrm{Y}_{2}\right)$.

Analisa Output :

1. Dari olah data tersebut didapat persamaan regresi linier sebagai berikut : $\mathrm{Y}_{2}=6.680+0.462 \mathrm{Y}_{1}+\mathrm{e}$. Arti persamaan tersebut adalah Konstanta 6.680 menyatakan jika tidak ada Adopsi E-commerce $\left(\mathrm{Y}_{1}\right)$ maka Keberhasilan Usaha $\left(\mathrm{Y}_{2}\right)$ sebesar 6.680. Koefisien Regresi 0.462 menyatakan bahwa setiap penambahan 1 point Adopsi Ecommerce $\left(\mathrm{Y}_{1}\right)$, maka Keberhasilan Usaha $\left(\mathrm{Y}_{2}\right)$ akan meningkat sebesar 0.462 .

2. Untuk uji parsial $Y_{1}$ didapat nilai signifikan $0,000<0,05$ (level of significant) maka dinyatakan menolak Ho artinya secara parsial terdapat pengaruh signifikan dan positif antara variabel Adopsi E-commerce $\left(\mathrm{Y}_{1}\right)$ dan variabel Keberhasilan Usaha $\left(\mathrm{Y}_{2}\right)$.

\section{Kesimpulan}

\subsection{Kesimpulan}

1. Hipotesis 1 menyatakan bahwa faktor manfaat mempunyai pengaruh signifikan dan positif terhadap pengadopsian $e$ commerce. Dalam penelitian ini diperoleh bukti empiris bahwa hubungan kedua variabel tersebut terbukti, sehingga dapat ditarik kesimpulan bahwa semakin tinggi manfaat maka pengadopsian e-commerce akan berjalan semakin baik.

2. Hipotesis 2 menyatakan bahwa faktor kemudahan penggunaan mempunyai pengaruh signifikan dan positif terhadap pengadopsian e-commerce. Dalam penelitian ini diperoleh bukti empiris bahwa hubungan kedua variabel tersebut. terbukti sehingga dapat ditarik kesimpulan bahwa semakin tinggi kemudahan penggunaan maka pengadopsian e-commerce akan berjalan semakin baik.

3. Hipotesis 3 menyatakan bahwa adopsi e-commerce mempunyai pengaruh signifikan dan positif terhadap keberhasilan usaha. Dalam penelitian ini diperoleh bukti empiris bahwa hubungan kedua variabel tersebut terbukti, sehingga dapat ditarik kesimpulan bahwa semakin tinggi adopsi e-commerce maka keberhasilan usaha akan semakin meningkat.

4. Dari hasil pengukuran jawaban responden mengenai faktor manfaat didapatkan 77pedagang batik $(80,2 \%)$ menyatakan sangat setuju dan setuju bahwa adopsi e-commerce bermanfaat. 
5. Dari hasil pengukuran jawaban responden mengenai kemudahan pengunaan didapatkan 86 pedagang batik $(89,6 \%)$ menyatakan sangat setuju dan setuju bahwa e-commerce mudah digunakan.

6. Dari hasil pengukuran jawaban responden mengenai adopsi $e$ commerce didapatkan 79 pedagang batik $(82,3 \%)$ menyatakan sangat setuju dan setuju bahwa adopsi e-commerce dapat meningkatkan penjualan, pangsa pasar dan pendapatan.

7. Dari hasil pengukuran jawaban responden mengenai keberhasilan usaha didapatkan 87 pedagang batik $(90,6 \%)$ menyatakan sangat setuju dan setuju bahwa dengan adopsi $e$ commerce dapat membantu dalam meningkatkan keberhasilan usaha.

\subsection{Rekomendasi}

\subsubsection{Bagi Pemerintah}

Hasil penelitian ini diharapkan dapat menjadi bahan masukan agar pemerintah dapat meningkatkan perannya sebagai penggerak utama yang merangsang berkembangnya $e$ commerce, yaitu dengan :

1. Mendorong dan memberdayakan pedagang batik sebagai komponen utama pengembangan $e$ commerce untuk memanfaatkan e-commerce dalam menunjang kegiatan usahanya.

2. Mengidentifikasi dan membantu pedagang batik yang akan menjadi perintis implementasi e-commerce, yang pada gilirannya pedagang batik yang menjadi perintis diharapkan akan menjadi pendorong bagi pedagang batik lainnya untuk ikut terjun ke $e$ commerce.

3. Memberikan stimulus terhadap pedagang batik mengenai manfaat $e$ commerce yang bisa menunjang aktivitas bisnisnya, misalnya dengan cara memberikan sosialisasi mengenai apa itu $e$ commerce, manfaat maupun peran e-commerce dalam menjaga keberlanjutan usahanya.

4. Memberikan pelatihan kepada pedagang batik untuk mengenal $e$ commerce serta seluk beluk pemasaran melalui internet.

\subsubsection{Bagi Pedagang Batik}

Hasil penelitian ini diharapkan dapat menjadi bahan masukan bahwa :

1. Kondisi yang riil, adopsi $e$ commerce dikalangan pedagang batik masih sangat rendah. Dengan meluasnya perdagangan global, tidak cukup bagi pedagang batik hanya dengan mengandalkan pemasaran secara konvensional.

2. Bagi pedagang batik yang terkendala masalah sumber daya manusia yang minim pengetahuannya tentang penggunaan e-commerce, maka pedagang batik perlu memperbaiki kualitas sumber daya manusianya 
agar dapat menggunakan $e$ commerce.

3. Pedagang batik perlu memperluas

pengetahuannya tentang bagaimana e-commerce dapat dimanfaatkan untuk meningkatkan keberhasilan usahanya.

4. Untuk keberlanjutan pemasarannya, pedagang batik disarankan untuk meningkatkan adopsi $e$ commerce dengan membangun website $e$ commerce milik pribadi yang disesuaikan dengan cost - benefit pada masingmasing pedagang batik.

\subsubsection{Bagi Peneliti Selanjutnya.}

1. Pada penelitian berikutnya dapat ditambahkan variabel baru untuk memperkaya penelitian tentang adopsi $e$ commerce dengan metode Technologi Acceptance Model (TAM) dikalangan pedagang batik, seperti misalnya variabel kemampuan menggunakan komputer (computer self efficacy), sikap terhadap penggunaan (attitude toward using), dan niat untuk menggunakan (intention to use) dalam adopsi $e$ commerce.

2. Objek yang dapat diteliti untuk penelitian lainnya disarankan untuk lebih beragam, mulai dari teknologi informasi yang meliputi perangkat keras (jaringan, input/output device), dan perangkat lunak (sistem informasi, aplikasi, bahasa pemrograman).

\section{Daftar Pustaka}

Adi, B. (2008). http://bambangriadi.com. Retrieved from Penerapan TI Memperkuat UKM India http://bambangriadi.com/br/2008/10/ penerapan-ti-memperkuat-ukm-india

Alter, S. (1992). Information System A Management Perspective. The Benjamin/Cummings Publishing Company Inc.

Benedicta Prihatin Dwi, R. (2003). Kewirausahaan Dari SUdut Pandang Psikologi Kepribadian. Jakarta: Grasindo.

Bonar, G. H. (1993). Accounting Information System (5th ed.). Prentice-Hall, Inc.

Davis, F. (1986). Perceived Usefulness, Perceived Ease Of Use And User Acceptance Of Information Technology. MIS Quarterly Vol. 13 No.3, 318-339.

Effendi, S. \&. (1989). Metode Penelitian Survey. Jakarta: LP3IS.

Ellsworth, J. H. (1997). Marketing on the Internet: Pemasaran Di Internet. Jakarta:: Grasindo,.

Fatmariani. (2011). Pengaruh Adopsi Teknologi Informasi Open Source E-commerce Terhadap Kinerja UKM dengan Faktor-Faktor Technology Acceptance Model (TAM) Sebagai Moderating Variabel. Jurnal Teknomatika Vol. 1 No. 1 Palembang STMIK PalComTech.

Ghozali, I. (2007). Aplikasi Multivariat Program SPSS. Semarang: Badan Penerbit Universitas Diponegoro.

Hasyim, J. (Desember 2007). Information Technology Adption Among SME Owners in Malaysia. International Journal of Business and Information Vol.2, No. 2. 
Jauhari, J. (April 2010). UPAYA PENGEMBANGAN USAHA KECIL DAN MENENGAH (UKM) DENGAN MEMANFAATKAN $E$ COMMERCE. Jurnal Sistem Informasi (JSI) VOL. 2, NO. 1, 159-168. Retrieved from http://ejournal.unsri.ac.id.

Jinling, C. e. (Oktober 2009). Modeling E-commerce Website Quality with Quality Function. IEEE International Conference on Deployment e-Business, 21-23 .

Karagozoglu, N. A. (2004). Electronic Commerce Strategy, Operation, And Performance In Small And Medium Sized Enterprises. Journal Of Small Business And Enterprises Development, 11(3), 290-301.

Kraemer, K. L., \& Gibbs, J. d. (2002). Impacts of Globalization on $E$ commerce Adoption and Firm Performance: A Cross-Country Investigation. Retrieved from http://www.crito.uci.edu.

Lee, K. K. (2003). he Technology Acceptance Model Past, Present,. Communication of The Association for Information System (CAIS) 12, 752-780.

Lucas, H. (2000). Information Technology for Management (7th ed.). Irwin/McGraw-Hill.

Machfoedz, M. (2005). Kewirausahaan : Metode, Manajemen, dan Implementasi. Yogyakarta: BPFE - Yogyakarta.

Malhotra, N. K. (2005). Riset Pemasaran : Pendekatan Terapan, Edisi 4. Klaten: Intan Sejati.

Martin, E. (1999). Managing Information Technology What Managers Need to Know (3rd ed.). New Jersey: Pearson Education International.

Mizar, A. d. (2008). Kerangka Konseptual Model Adopsi
Teknologi Untuk Industri Kecil Pengolahan Hasil Pertanian. Jurnal Teknologi dan Manajemen Informatika Universitas Merdeka Malang Fakultas Teknologi Informasi.

Rietveld, S. d. (1987). Adopsi inovasi pada industri kecil. Nomor 4. Prisma, halaman 57- 66.

Roger, E. (1995). Diffusion of Innovation (4th Edition). New York: The Free Press.

Sevtian, F. I. (2011). Pengaruh Ecommerce Terhadap Tingkat Volume Penjualan Sandal Kelom Geulis Di CV Kelomgeulis Tasikmalaya. Skripsi . Jakarta: FPEB Universitas Pendidikan Indonesia.

Sugiyono. (2009). Statistik Untuk Penelitian . Bandung: CV. Alfabeta.

Turban, E., King, D., Lee, J., Warkentin, M., \& Chung, H. M. (2002). Electronic Commerce : A Managerial Perspective (International Edition).

Venkat, R. (2000). A Study on the Impact of Business-to-Business Ecommerce in. Retrieved from http://www.pmac.ca/PDF/ste\%20mar ys\%study.pdf.

Venkatesh, V. M. (2003). User acceptance of information technology : Toward a unified view. MIS Quarterly 27(3), 425478.

Yuliana, O. Y. (2000, Mei). Penggunaan Teknologi Internet Dalam Bisnis. Retrieved from puslit2.petra.ac.id. http:/www.puslit2.petra.ac.id/gudan gpaper/files/1745.pdf

Yun. (1999). E-commerce Solusi UKM Atasi Krisis. Retrieved from http/www.kompas.com 